\title{
EL POBLAMIENTO ARGÁRICO DE LAS HERRERÍAS (CUEVAS DE ALMANZORA, ALMERÍA), SEGÚN LA DOCUMENTACIÓN INÉDITA DE L. SIRET
}

\author{
THE ARGARIC SETTLEMENT AT LAS HERRERÍAS (CUEVAS DE ALMANZORA, \\ ALMERÍA), BASED ON UNPUBLISHED L. SIRET'S NOTES
}

\section{DIRK BRANDHERM $(*)$}

\section{RESUMEN}

En Las Herrerías L. Siret documentó durante el curso de labores de minería en las primeras décadas de nuestro siglo restos de tumbas y viviendas tanto del Calcolítico como de la Edad del Bronce. Sus escasas notas son hoy día los únicos testimonios de la ocupación prehistórica del lugar, privado en la actualidad de todo su anterior potencial arqueológico por la destrucción producida por las actividades industriales del siglo XIX y de la primera mitad del siglo XX.A partir de sus notas y de los pocos hallazgos rescatados por él, se puede reconstruir para la Edad del Bronce un poblamiento aparentemente importante pero sin un núcleo de características urbanas, estructurado más bien de manera abierta y dispersa. El modo aislado y poco sistemático como el propio Siret y varios autores posteriores fueron dando a conocer distintos datos sobre los conjuntos funerarios de Las Herrerías, así como la mezcla de materiales de dos de las tumbas durante los años cincuenta, cuando ya habían ingresados en el Museo Arqueológico Nacional, ha creado cierta confusión con respecto a los ajuares respectivos y su cronología relativa y absoluta. El presente articulo pretende ofrecer una sinopsis sistemática de los materiales conservados y de la información recogida en las notas de L. Siret, para corregir estos errores y llamar la atención sobre los asentamientos litorales de la cultura argárica en general, categoría de poblados muy amenazados por la acción tanto de la naturaleza como del hombre y generalmente infravalorados por la investigación.

(*) Becario postdoctoral. Dpto. de Prehistoria y Arqueología. Universidad Autónoma de Madrid. Ciudad Universitaria de Canto Blanco. 28049 Madrid.

El artículo fue remitido en su versión final el 17-VI-99.

\begin{abstract}
During the first decades of this century, L. Siret documented a series of Chalcolithic and Bronze Age remains at Las Herrerías that were discovered (and subsequently destroyed) by mining operations of the time. Today his notes constitute the only evidence for what once must have been a fairly rich archaeological locality. Based on Siret's notes and the few finds he managed to rescue, we can reconstruct it as an open and rather dispersed, though certainly large, settlement that lacks the tightly knit, nuclear structure with almost urban features displayed by most other known Argaric habitation sites. The haphazard and unsystematic way in which Siret documented the funerary remains, and in which he and later authors published them, has led to some confusion about the actual composition of the assemblages and about their relative and absolute chronology. Also contributing to this confusion was a mixing of materials from two of the graves that occurred in the 1950s, after the finds had been deposited in the National Museum of Archaeology in Madrid. The present contribution seeks to give a systematic account of the site based on Siret's notes and the surviving finds in order to sort out these problems and to call special attention to the coastal settlements of the El Argar Culture, which have been hitherto largely ignored by archaeologists and which are currently endangered by a variety of natural factors and human actions.
\end{abstract}

Palabras clave: Bronce Antiguo. Cultura de El Argar. Poblamiento litoral. Sepulturas en cista.

Key words: Early Bronze Age. El Argar culture. Coastal settlement. Cist-graves. 


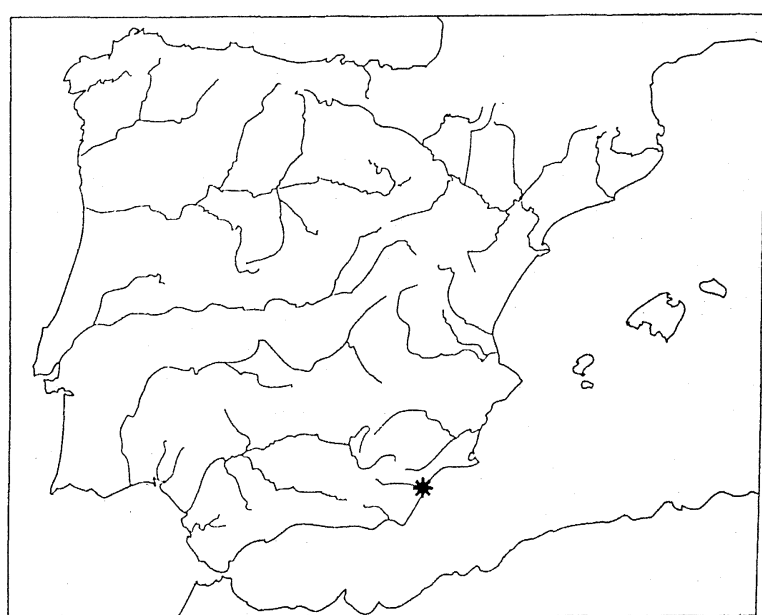

Fig. 1. Localización de Las Herrerías en el ámbito de la Península Ibérica.

\section{INTRODUCCIÓN (1)}

El presente artículo persigue un doble objetivo. Por un lado pretende dar a conocer de una forma organizada y coherente lo poco que se sabe de la ocupación argárica de Las Herrerías (Fig. 1). Últimamente su yacimiento principal, el Cerro Virtud, ha proporcionado los vestigios más antiguos de procesos metalúrgicos en el Mediterráneo occidental, fechados en elV milenio a.C. (Montero Ruiz y Ruiz Taboada, 1996: 65-74). Por el contrario, los restos materiales de la cultura de ElArgar, aparecidos allí en los trabajos de minería sobre todo durante las primeras décadas de nuestro siglo, son mucho menos conocidos. Sólo existen como referencias unos breves apuntes de L. Siret, quien recogió las noticias sobre hallazgos según fueron apareciendo en las obras. Al contrario de la gran mayoría de yacimientos investigados por los hermanos Siret, en Las Herrerías, localidad donde ellos mismos vivieron, nunca llegaron a realizar excavaciones sistemáticas, con la notable excepción deAlmizaraque, situado a unos centenares de metros del núcleo minero, ya en plena Vega del bajo Almanzora. Las actividades documentadas por L. Siret en este caso claramente tienen carácter de "intervenciones de urgencia" en determinados puntos ante la inminente destrucción

(1) Queremos expresar nuestro agradecimiento a la Dra. Dña. Carmen Cacho por facilitarnos la posibilidad de efectuar este estudio, así como también a Dña. Pilar Martín por su ayuda en la consulta de los expedientes correspondientes en el archivo del MAN y finalmente a Ignacio Montero por sus valiosos indicaciones sobre aspectos generales del yacimiento y su esfuerzo en ayudarnos a mejorar nuestro deficiente castellano. del yacimiento por las obras de la propia empresa para la que trabajaba.

El segundo objetivo es llamar la atención sobre el papel del hábitat litoral de la cultura argárica en general, una categoría de poblados poco conocidos y al mismo tiempo más amenazados que otros, tanto por factores naturales como por la propia acción humana. Como hábitats "litorales" se definen aquí aquellos yacimientos con acceso directo al mar, i.e. con un acceso no obstruido por la propia topografía ni controlado por otros asentamientos contemporáneos. Para la cultura argárica actualmente no se conocen demasiados poblados dentro de esta categoría. Sólo existen unos cuantos en todo el Sudeste; exceptuando Las Herrerías se trata principalmente de la Illeta dels Banyets o Isleta de Campello, situado ya al norte deAlicante, en el margen septentrional de la "área cultural" de El Argar (Simón García, 1997: 49-63), así como de una serie de yacimientos no muy bien conocidos de la fachada litoral granadina-malagueña: el Castillo de Salobreña, La Herradura, el Cerro de Velilla, Puente Noy y el Pago del Sapo deAlmuñecar (Granada), así como el Lagar de las Animas y posiblemente el Cerro de San Telmo (Málaga), yacimientos que reflejan una amplia variedad de situaciones topográficas (Lull, 1983:386388; Molina Fajardo, 1983: 3-20; Ruiz Morales y Molina Poveda, 1996: 179; BaldomeroNavarro et alii, 1985: 121-133; Baldomero Navarro et alii, 1988: 153-154).

Los restos argáricos documentados en Las Herrerías se concentran en las inmediaciones del Cerro Virtud, elevación de $68 \mathrm{~m}$ de altura, situado directamente al sur de la actual población y a circa 2,8 $\mathrm{Km}$ de la desembocadura del ríoAlmanzora, sobre su margen izquierdo. Durante el Calcolítico y el Bronce Antiguo el mar muy probablemente se encontraba a menos de $1 \mathrm{Km}$ del yacimiento (Arteaga et alii, 1988: 111-113, fig. 2). L. Siret en sus notas distingue varios hallazgos por referencias a las distintas minas y concesiones mineras en que aparecieron; para la cultura argárica registra restos en las concesiones de la Mina Alianza, Mina Diana y Mina Iberia (vease Montero Ruiz, 1994: fig. 5). Sólo la cista de la Mina Iberia fue publicada por Siret (1913: lám. 13. 14); los restos argáricos de las minas Alianza y Diana quedaron inéditos, salvo unas breves menciones a partir de los años cincuenta, que causaron una cierta confusión en cuanto a la composición exacta de los distintos conjuntos de materiales (Fig. 2).

En la gran obra de catalogación de Schubart y 


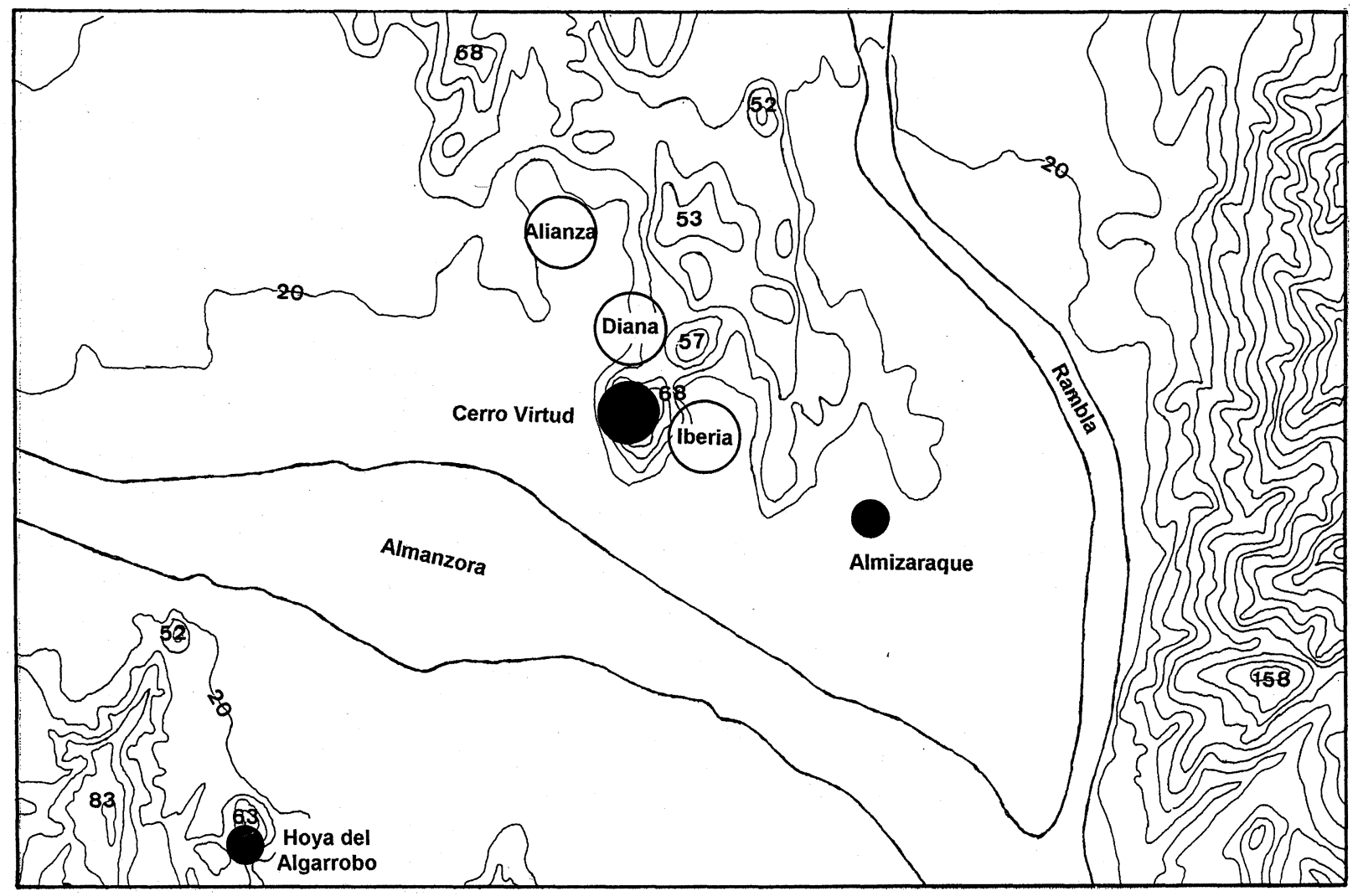

Fig. 2. Localización de las distintas concesiones mineras de Las Herrerías en que aparecieron los restos argáricos documentados por L. Siret y demás yacimientos mencionados en el texto, 1: 25.000 .

Ulreich (1991), que aspiró a documentar todos los materiales argáricos de la antigua Colección Siret, lamentablemente no se incluye ninguna referencia a los hallazgos de Las Herrerías, a pesar de que la cista de la Mina Iberia-publicada ya en su época por el mismo L. Siret-así como algunos elementos del material de la Mina Alianza formaban parte de la exposición permanente del Museo Arqueológico Nacional (MAN) a partir de los años cincuenta. Esta ausencia se debe muy probablemente a la desafortunada circunstancia que los materiales no salieron en el curso de excavaciones regulares, proyectadas como en otros yacimientos por los hermanos Siret y realizadas bajo la dirección de su capataz Pedro Flores, sino como fruto ocasional de los trabajos mineros en Las Herrerías. Por esa misma razón no se encuentran descritos en los cuadernos de campo del competente y bastante minucioso Pedro Flores, aunque existen algunas hojas sueltas, fotos y croquis de la mano de L. Siret, conservados hoy día en el archivo del MAN (Lám. I y II). En los siguientes párrafos se expondrán por primera vez de manera completa y sistemática las informaciones que poseemos sobre las sepulturas y los vestigios del hábitat argárico de Las Herrerías a partir de esas notas de L. Siret y de los materiales de su colección conservados en los fondos del MAN.

\section{LAS SEPULTURAS}

Las tumbas argáricas de Las Herrerías han sido mencionadas con bastante frecuencia en la bibliografía especializada y empleadas en sus respectivos argumentos por varios autores, pero nunca fueron descritas de una manera sistemática, lo que ha causado una creciente confusión en cuanto a su ajuar exacto y detalles de los hallazgos. Recientemente Castro Martínez et alii (1993/94: 93, nota 30) intentaron aclarar el asunto, pero al escapárseles o desconocer algunos detalles de la historia de los conjuntos respectivos, mantienen algún error que en el futuro pudiera conducir a nuevos malentendidos. Estos errores se deben probablemente a que estos 


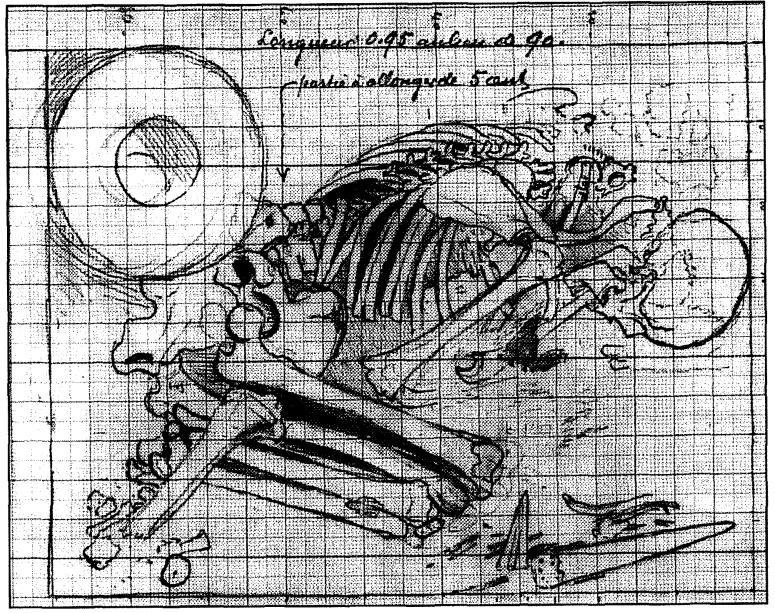

Lám. I. Croquis de la mano de L. Siret de la sepultura ${ }^{\circ}$ 1 de la Mina Iberia (Archivo del MAN).

autores tampoco estudiaron personalmente el material en el MAN, y sólo dispusieron de fotocopias de la documentación. En efecto, es precisamente algún detalle, obvio con el original de la documentación fotográfica de L. Siret pero quizá no tan fácil de observar en una fotocopia, el que permite aclarar un problema fundamental con el hallazgo de la Mina Iberia, y puede conllevar serias consecuencias en cuanto a la cronología relativa de este conjunto de materiales.

En la fotografía vertical de la cista (Lám. III), tomada por L. Siret antes de que la alabarda cambiase accidentalmente su posición al quitar una de las lajas laterales para la toma de la foto horizontal (Lám. IV), se aprecia que la pieza en cuestión poseía por lo menos cinco remaches y no dos, como

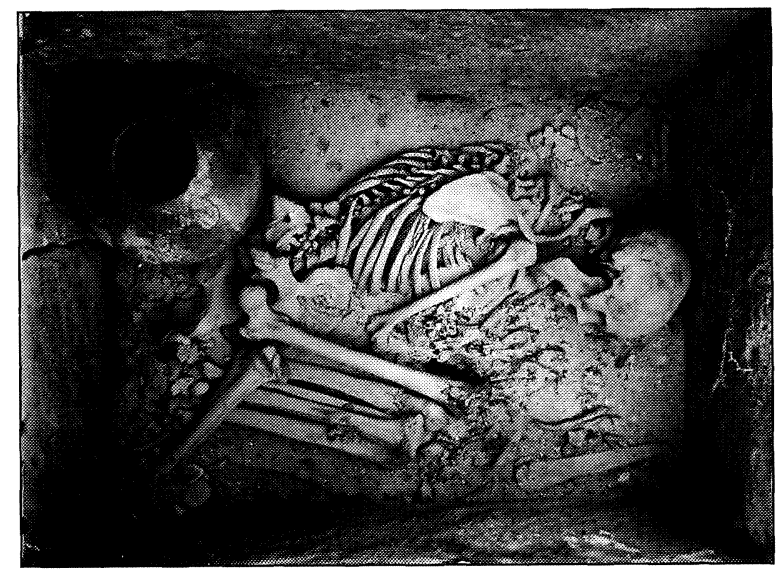

Lám. III. Sepultura ${ }^{\circ} 1$ de la Mina Iberia, vista vertical, en una foto de L. Siret (Archivo del MAN).

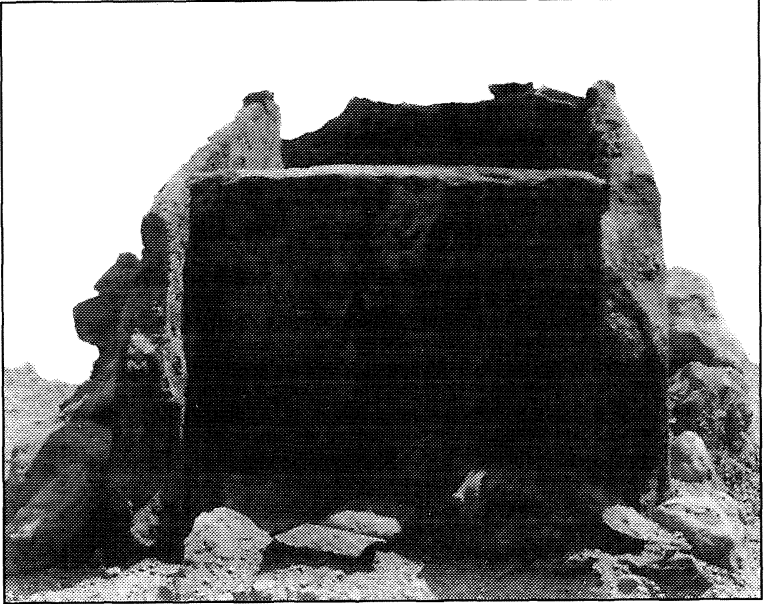

Lám. II. Sepultura ${ }^{\circ} 1$ de la Mina Iberia después de bajar el terreno adyacente, en una foto de L. Siret (Archivo del MAN).

tiene la alabarda que acompaña al ajuar de la cista de la Mina Iberia en la exposición permanente del MAN. En un detalle ampliado de la foto de Siret, los remaches se observan nítidamente como puntos algo más claros sobre el fondo gris oscuro de la misma alabarda (Lám.V). También parece más estrecha que el arma expuesta durante largos años con los demás materiales de la cista y publicada por Castro Martínez et alii (1993/94: fig. 11) como perteneciente a este ajuar. La argumentación sobre la no identidad de esa pieza con la encontrada por Siret en la cista de la Mina Iberia en el momento de su descubrimiento, y que seguramente se trata de una confusión de dos alabardas distintas, no sólo se basa en la evidencia fotográfica, sino también en una información textual a la que más abajo nos vamos a referir detenidamente, ya que permite aclarar también otra duda sobre un conjunto de materiales procedentes de la MinaAlianza.

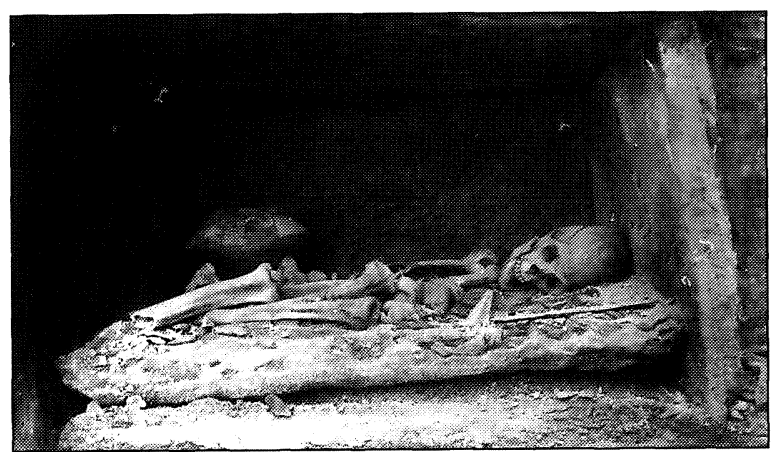

Lám. IV. Sepultura ${ }^{\circ} 1$ de la Mina Iberia, vista horizontal, en una foto de L. Siret (Archivo del MAN). 


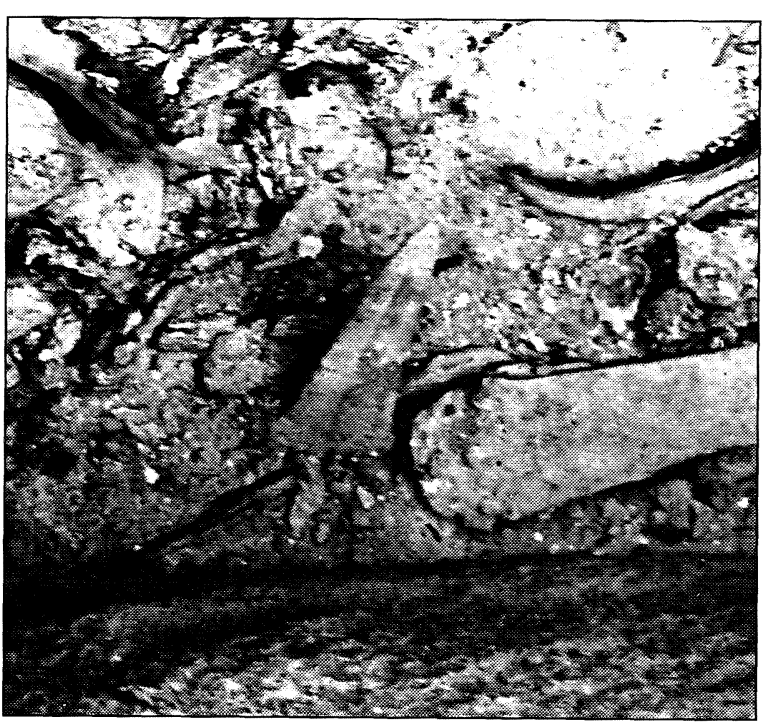

Lám.V. Detalle de la sepultura ${ }^{\circ} 1$ de la Mina Iberia (Archivo del MAN).

Un problema importante que parte de esta confusión de piezas es la fecha de carbono 14 de $1720 \pm 70$ bc (CSIC-248), obtenida de materia orgánica del interior de la cista, que se ha utilizado por tanto incorrectamente para fechar al tipo de la alabarda con dos remaches (véase Almagro Gorbea, 1976: 464; Lull, 1983: 245-246; Castro Martínez et alii, 1993/94: 91-93, tab. 1, 34, fig. 11). Obviamente, en los intentos de establecer una cronología tanto relativa como absoluta de este ajuar, debe tomarse en cuenta que la alabarda con dos remaches no forma parte del conjunto.

¿Que pasó entonces con la pieza que Siret encontró como parte del ajuar de la cista de la Mina Iberia y que documentó en su fotografía? Efectivamente el autor del presente artículo logró localizar entre los fondos del MAN (caja 1413), como pieza suelta de la Colección Siret, una alabarda con procedencia de la Mina Iberia que tiene su zona de enmangue bastante dañada, pero que en un principio poseía un mínimo de cinco remaches. Con toda probabilidad es esta la pieza que figura en las fotografías tomadas por L. Siret y que por tanto pertenece al ajuar de la cista de la Mina Iberia (Fig. 3).

Otra de las sepulturas, la cista de la Mina Alianza, a la cual desde aquí en adelante nos vamos a referir como sepultura 1 de la Mina Alianza, en un principio no presenta tantos problemas. La tumba no fue publicada por Siret, pero en el archivo del MAN se conservan sus notas sobre el hallazgo y un croquis de su mano (Lám.VI). Tampoco entró en la bibliografía posterior, con la excepción de una breve men-

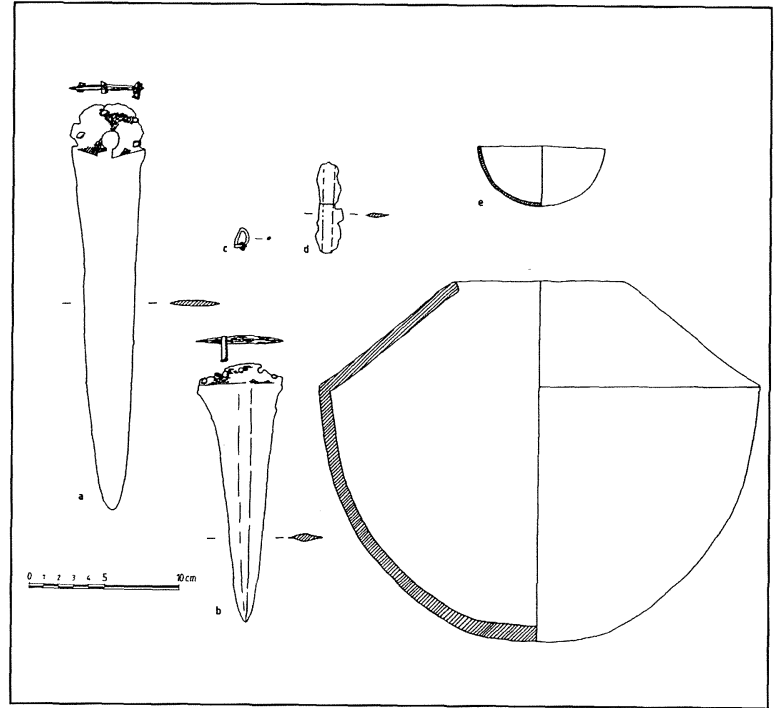

Fig. 3. Ajuar de la sepultura $\mathrm{n}^{\circ} 1$ de la Mina Iberia.

ción por Castro Martínezet alii (1993/94: nota 30) y de dos referencias recientes a la composición metalúrgica del puñal que forma parte del ajuar de esta tumba (Montero Ruiz, 1994: 128. 364, $\mathrm{n}^{\circ}$ AA1182; Rovira Llorens et alii, 1997: 69, $\mathrm{n}^{\circ}$ AA1182). No obstante, aquí también existe una cierta confusión sobre la que hay que llamar la atención. Como veremos enseguida, la adscripción al ajuar de esta cista por parte de Castro Martínez et alii (1993/ 94: nota 30) de dos vasos carenados que en el libro guía del MAN de los años cincuenta aparecen como procedentes de la MinaAlianza (Guía, 1954: lám3) constituye otro error que debe eliminarse. Estos autores sospechan que los materiales de la antigua Guía del MAN (Lám. VII) de la Mina Alianza no

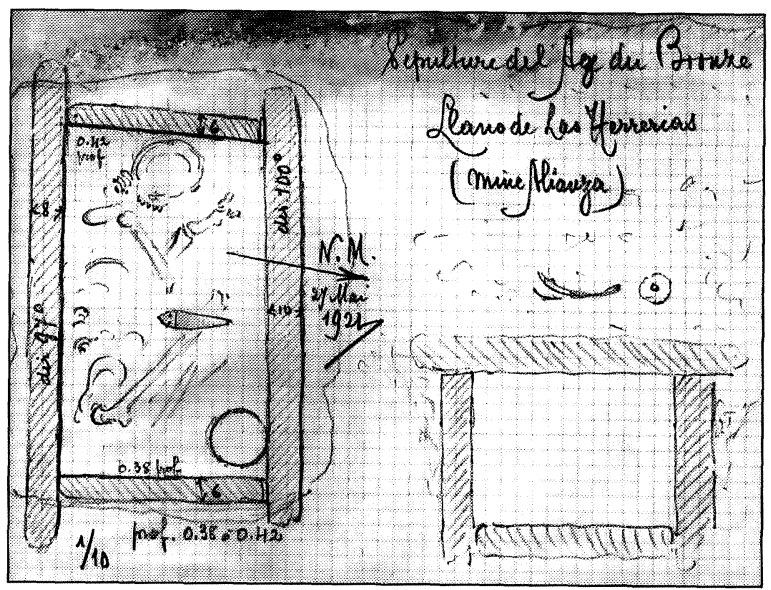

Lám. VI. Croquis de la mano de L. Siret de la sepultura $\mathrm{n}^{\circ} 1$ de la Mina Alianza (Archivo del MAN). 


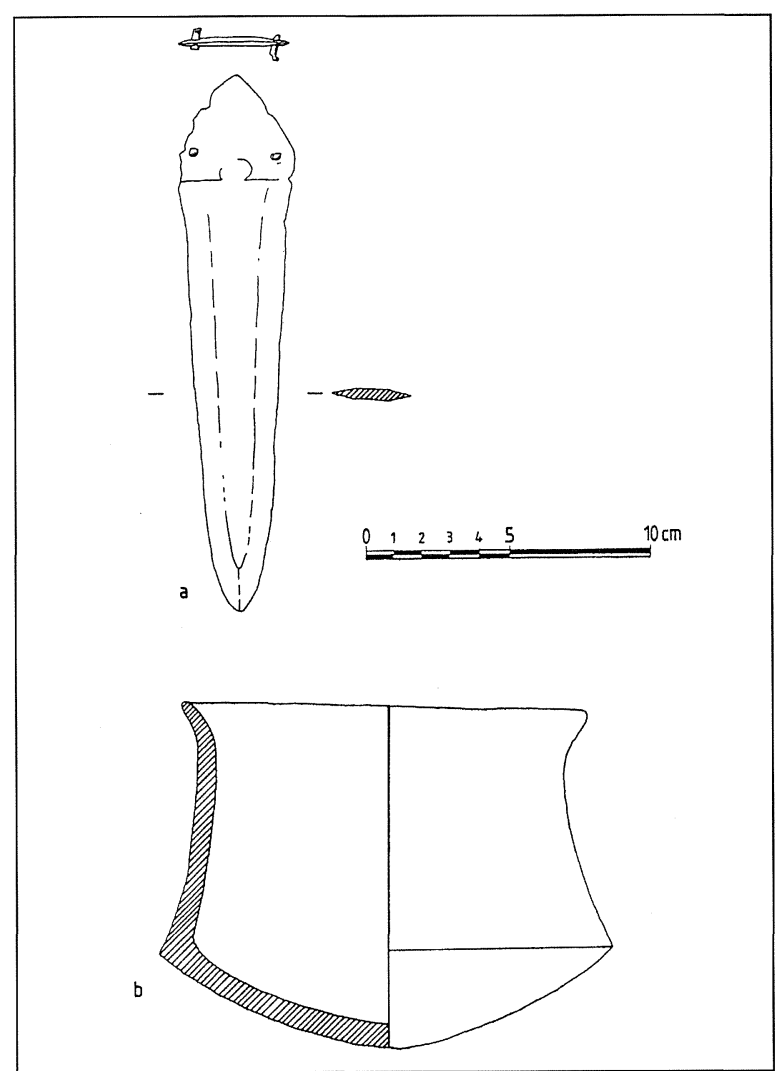

Fig. 4. Ajuar de la sepultura $\mathrm{n}^{\circ} 1$ de la Mina Alianza.

constituyen ningún conjunto real en si mismo. Por causa de la-como ya pudimos ver-falsa atribución de la alabarda de dos remaches a la tumba de la Mina Iberia asumen erróneamente que esta pieza no puede pertenecer al conjunto ahí representado. Por la misma razón, y sin más argumentos, suponen que las dos tulipas en esa lámina debieran pertenecer a la sepultura 1 de la MinaAlianza y que el puñal, que aparece asociado a estos materiales, pertenece a otro conjunto distinto que no tiene nada que ver con las demás piezas. Pero ya hemos visto que, en realidad, la alabarda en cuestión seguramente nunca formó parte del ajuar de la cista de la Mina Iberia, ya que se trata de una confusión ocurrida a partir de los años cincuenta. Igualmente no existen argumentos para adscribir los dos vasos carenados a la cista de la MinaAlianza, hallazgo suficientemente bien documentado en los papeles de Siret (Expediente del MAN: Col. Siret/caja 14/AD.1-AD.21). Por el contrario, ahí consta con toda claridad que en aquella tumba apareció un solo vaso, que ademas está conservado en los fondos del MAN y no corresponde a ninguno de los vasos presentados en la Guía(Fig.4).

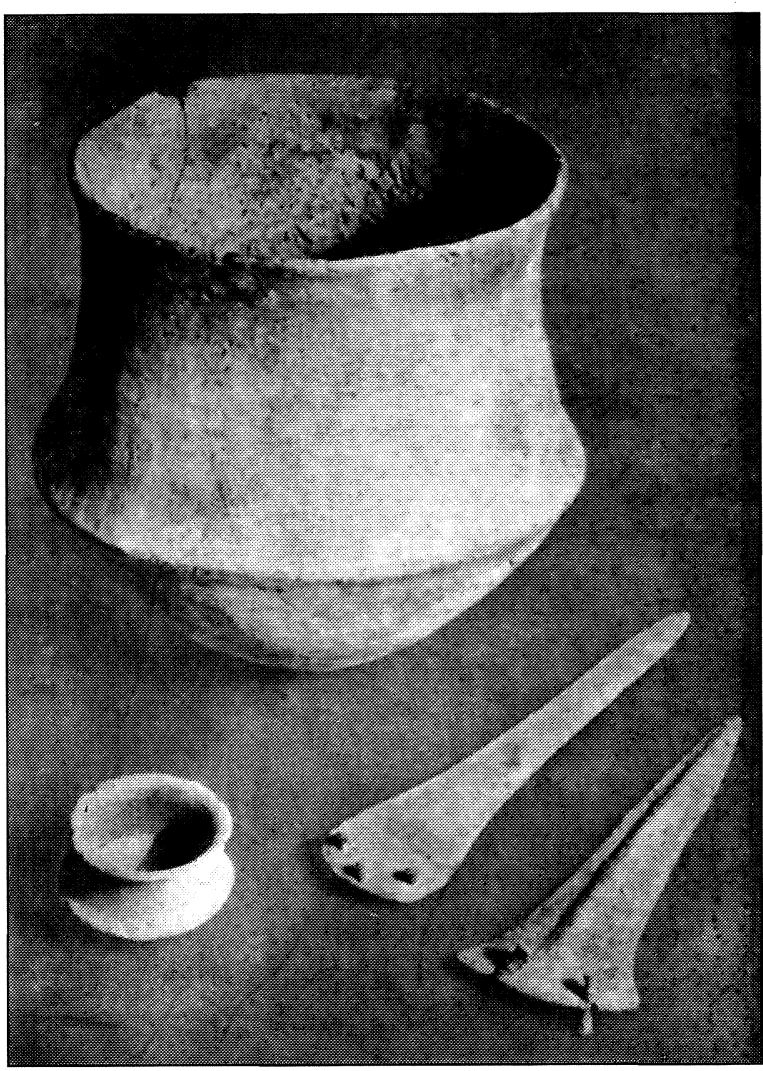

Lám. VII. Ajuar de la sepultura ${ }^{\circ} 2$ de la Mina Alianza (según Guía, 1954: lám. 3).

Apesar de estos problemas tenemos la suerte que el texto de la Guía nos aclara cómo se produjo la confusión entre la alabarda de la Mina Iberia y la pieza que figura en su lámina: "En la sala I, y perteneciente al yacimiento de ElArgar de esta colección, hay un sepulcro de cista con su ajuar completo, excepto la alabarda que pertenece al yacimiento de Alianza (Herrerías) y está en sustitución de la que había colocado don Luis Siret, que era de cartón" (Guía, 1954: 188). Aquí lo extraño es que el texto habla de una cista del yacimiento de El Argar, lo que no corresponde bien a las demás informaciones, según los cuales la cista argárica de la Mina Iberia siempre fue el único sepulcro de este tipo expuesto en el MAN. Tampoco la misma Guía habla de otra cista en la exposición, y según todas las informaciones que poseemos, Siret no se quedó en su casa con ninguna cista completa del yacimiento de El Argar. En su publicación de la cista de la Mina Iberia, por el contrario, consta de manera explícita que mandó llevar la cista completa con todas las lajas a su casa, aprovechando que estaba a sólo unos centenares de metros (Siret, 1913: lám. 13. 14). Por 


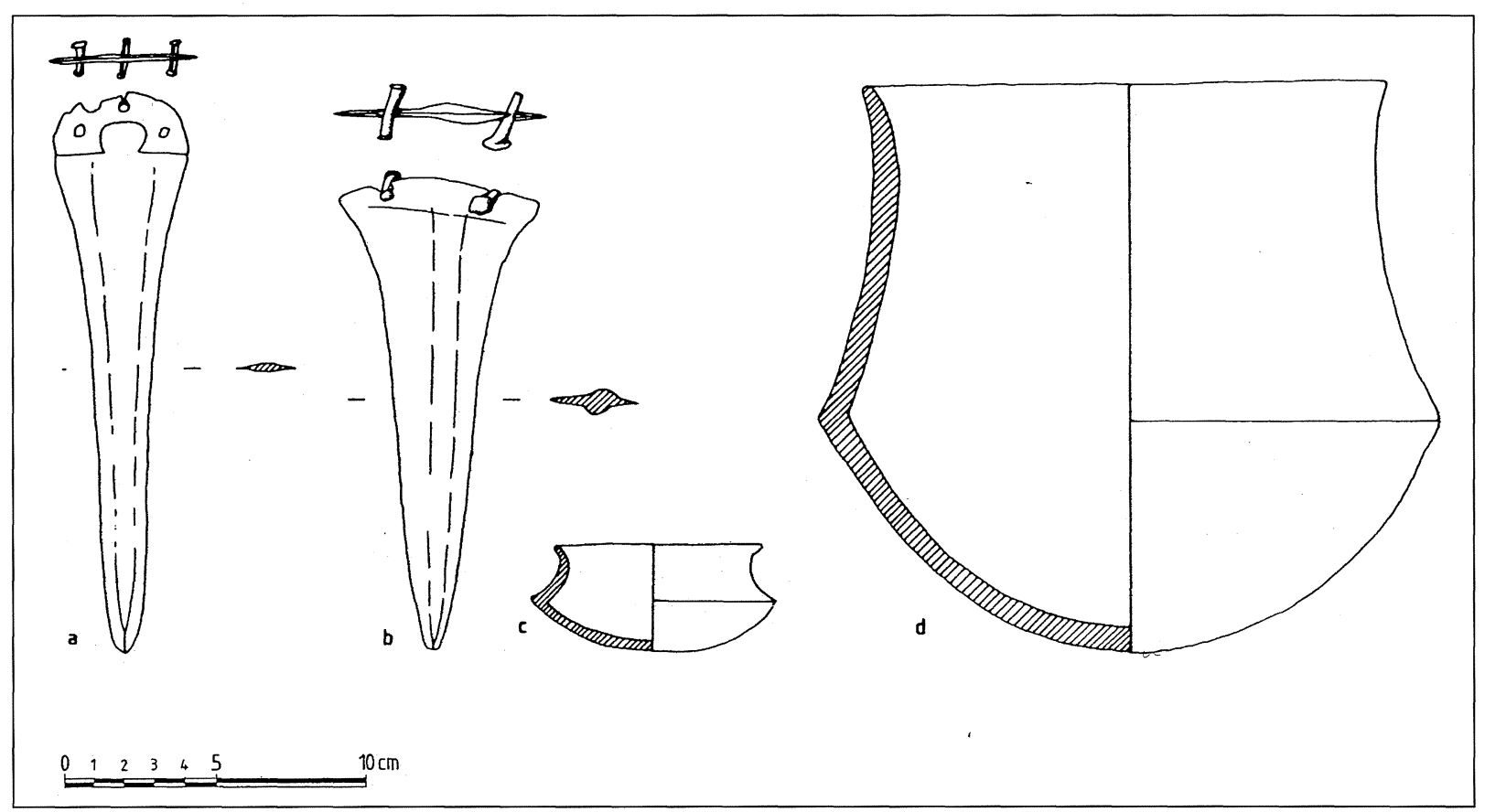

Fig. 5. Ajuar de la sepultura ${ }^{\circ} 2$ de la Mina Alianza.

esa razón, cuando se habla en la Guía de una cista del yacimiento de ElArgar, parece tratarse casi seguro del mismo error que llevó a la atribución de la fecha de carbono 14 con el código del laboratorio CSIC-248 al yacimiento de El Argar, sin que hoy aún nos sea posible averiguar el origen de este error (vease Castro Martínez et alii, 1993/94: 93, nota 29). También se nos resiste el motivo por el que el propio Siret llegó a colocar una alabarda de cartón en la cista de la Mina Iberia, guardando la pieza original aparte.

Cabe entonces la pregunta de cómo valorar los materiales que figuran en la lámina de la Guía. En el pie de la lámina sólo se habla de Herrerías como procedencia, pero en el texto se nos afirma que se trata de otra sepultura de la Mina Alianza. Esta sepultura no viene mencionada en los papeles del legado Siret, pero no sabemos si la documentación preservada en el MAN en este caso está completa. En relación con otros yacimientos, donde el mismo Siret numeraba los cuadernos o dejó índices, a veces, aunque no muy a menudo, se puede confirmar el carácter incompleto de la documentación conservada. Una posible confusión con materiales de una tumba de El Argar, que quizá se pudiera sospechar por la mención enigmática de este yacimiento en el texto arriba citado de la Guía, se puede excluir por una razón muy sencilla. Según los cua- dernos de campo de Pedro Flores, en la Colección Siret no debiera existir ninguna sepultura perdida del yacimiento epónimo con un ajuar de tales características.

Dado el carácter casual de los hallazgos aparecidos en las obras de minería en Las Herrerías, parece bien posible que la única referencia a la procedencia de este conjunto consistiera en una nota guardada junto con los materiales y perdida cuando se incorporaron a la exposición permanente del MAN. Provisionalmente de aquí en adelante nos vamos a referir a este conjunto como sepultura 2 de la Mina Alianza (Fig. 5). Bajo estas circunstancias no será posible hacer comentarios sobre el tipo y carácter de la tumba o afirmar si los elementos presentados en la Guía constituyen el ajuar completo. Tampoco podemos deducir del texto de la Guía si se trataba de una cista o de otro tipo de enterramiento.

Aparentemente no hay evidencias de otras tumbas argáricas en las inmediaciones del Cerro Virtud. En el caso de una cista "argárica" en los estratos superiores del cercano yacimiento de Almizaraque, excavada por Almagro Basch (1965: 379) y según sus informaciones tentativamente atribuido por nosotros (Brandherm, 1998: 196-170) a una fase formativa de la cultura de ElArgar, no se debe tratar en absoluto de una estructura de la Edad del 
Bronce. Según los resultados de las excavaciones realizadas enAlmizaraque durante los años ochenta bajo la dirección de M. Fernández-Miranda y G. Delibes de Castro, aquella "cista" en realidad sólo puede corresponder a una de las tumbas de lajas de época medieval, de las cuales se detectaron varias en el yacimiento (Delibes et alii, 1996: nota 4).

\section{DESCRIPCIÓN DE MATERIALES FUNERARIOS}

El siguiente listado relata los restos argáricos con carácter funerario de Las Herrerías según fueron mencionados por L. Siret en sus apuntes o conservados entre los materiales de su colección, hoy día guardada en el MAN. El listado se presenta por orden alfabético según el nombre de las minas y según conjuntos de materiales, acompañados por la respectiva bibliografía:

\section{Mina Alianza (sep. 1)}

Se trata de una cista de seis lajas, aparecida el 27 de mayo 1921 debajo de los restos de una casa ( $i$ argárica?), con medidas interiores de 90 por $55 \mathrm{~cm}$, orientada en dirección E/SE-OE/NOE. El esqueleto se encontró en posición muy flexionada, un puñal en cima del muslo y un vaso en la esquina inferior delante del muerto (Expediente del MAN: Col. Siret/ caja 14/ AD.1-AD.21) (Lám. VI) (2).

Elementos del ajuar:

- puñal de cuatro remaches (tipo AC 1); base triangular; remaches de las dos escotaduras proximales perdidas; los dos remaches conservados presentan sección cuadrada y redonda respectivamente, bordes de la hoja biselados; huella de enmangue con un escote en forma de omega; cobre arsenicado; longitud $18 \mathrm{~cm}$; ancho máx. $4 \mathrm{~cm}$; grosor (hoja) $0.35 \mathrm{~cm}$, (empuñadura) $0.33 \mathrm{~cm}$; peso $80 \mathrm{gr}$; longitud remaches $0.92-1.05 \mathrm{~cm}$; grosor remaches 0.34 $0.42 \mathrm{~cm}\left(\mathrm{n}^{\circ}\right.$ inv. 1984/158/MA/2) (Fig. 4a)

- vaso carenado (forma $5 \mathrm{~b}$ ); forma un poco irregular con color cambiante entre marrón-oscuro y negro; superficie bien alisada pero fuertemente erosionada en un lado del recipiente; desgrasante cuarzo de grano pequeño hasta medio; diámetro boca

(2) Para la terminología de las formas cerámicas véase Schubart y Arteaga (1986: 295), para la tipología del ajuar metálico véase Brandherm (en prensa).
$14.1 \mathrm{~cm}$; diámetro máx. $15.2 \mathrm{~cm}$; altura $12.2 \mathrm{~cm}$ ( ${ }^{\circ}$ inv. 1984/158/MA/1) (Fig. 4b)

- varios huesos de animales (no conservados)

Bibliografía: Castro Martínez et alii, 1993/94: 93, nota 30; Montero Ruiz, 1994: 128. 364, $\mathrm{n}^{\circ}$ AA1182; Rovira Llorens et alii, 1997: 69, $\mathrm{n}^{\circ}$ AA1182.

\section{Mina Alianza (sep. 2)}

La fechà del hallazgo, el tipo de la construcción de la tumba y todos los detalles del enterramiento son desconocidos. La sepultura se encuentra sin documentación en los expedientes del MAN que hacen referencia a la Colección Siret (Lám.VI).

Elementos del ajuar:

- puñal de tres remaches (tipo AB 6); base redondeada; remaches de sección cuadrangular; bordes de la hoja bien biselados; huella de enmangue en forma de omega con tendencia trapezoidal; cobre arsenical; longitud $18.1 \mathrm{~cm}$; ancho $4.6 \mathrm{~cm}$; grosor (hoja) $0.31 \mathrm{~cm}$, (empuñadura) $0.26 \mathrm{~cm}$; peso 66 gr; longitud remaches $1.76-1.92 \mathrm{~cm}$; grosor remaches $0.28-0.29 \mathrm{~cm}$ ( $\mathrm{n}^{\circ}$ inv. 1984/158/MA/6) (Fig. 5a)

- alabarda de dos remaches (tipoAA 20); base ligeramente oblicua; ambos agujeros rotos, pero remaches conservados; hoja con nervio central bastante acentuado, menos acentuado en la zona del enmangue, debido a un defecto de fundición no totalmente simétrico en ambas caras; huella de enmangue ligeramente oblicua; cobre arsenicado con alto porcentaje de arsénico; longitud $15.3 \mathrm{~cm}$; ancho $6.6 \mathrm{~cm}$; grosor (hoja) $0.91 \mathrm{~cm}$, (empuñadura) $0.43 \mathrm{~cm}$; peso $123 \mathrm{gr}$; longitud remaches 1.97-2.00 $\mathrm{cm}$; grosor remaches $0.31-0.38 \mathrm{~cm}\left(\sin \mathrm{n}^{\circ}\right.$ inv.) (Fig. 5b)

- vaso carenado pequeño (forma 5 a-1); de pared fina y superficie bien alisada hasta bruñida; con su parte superior ligeramente irregular y borde algo dañado; cocción irregular, oscilando entre zonas marrón-rojizas y negras oscuras; desgrasante mica muy fina; diámetro boca $6.4 \mathrm{~cm}$; diámetro máx. 7.9 $\mathrm{cm}$; altura $3.4 \mathrm{~cm}$ ( $\mathrm{n}^{\circ}$ inv. 1984/158/MA/5)(Fig. 5c)

- vaso carenado grande (forma $5 \mathrm{~b}$ ); con borde algo dañado; de superficie bien alisada, parcialmente erosionada en su parte inferior; de color marrón claro oscilando hacia negro en algunas zonas; desgrasante cuarzo de grano medio; diámetro boca $16,8 \mathrm{~cm}$; diámetro máx. $19.7 \mathrm{~cm}$; altura $18.5 \mathrm{~cm}\left(\mathrm{n}^{\circ}\right.$ inv. 1984/158/MA/4) (Fig. 5d)

T. P., 57, n. ${ }^{\circ} 1,2000$ 
Bibliografía: Guía, 1954: 188, lám. 3; Junghans et alii, 1968 a: lám. 54, 2293; Junghans et alii, 1968 b: 50-51, ${ }^{\circ}$ 2293; Blance, 1971: 185; Schubart, 1973: nota 12; Junghans et alii, $1974,368, \mathrm{n}^{\circ} 2293$; Schubart, 1975: 87 nota 34; Lull, 1983: 191; Montero Ruiz, 1994: 127-128, 364, $\mathrm{n}^{\circ}$ AA1120, AA1148A, AA1148B; Rovira Llorens et alii, 1997: 69, n AA1120, AA1148A, AA1148B.

\section{Mina Iberia (sep. 1)}

Enterramiento en cista, encontrado circa $1 \mathrm{~m}$ debajo de la superficie en el mes de agosto del año 1911. La medida de la profundidad posiblemente ya se encontraba afectada por las obras de minería. La cista estaba construida con seis lajas, con unas medidas interiores de 0.90 por $0.65 \mathrm{~cm}$. El esqueleto estaba fuertemente flexionado sobre su lado izquierdo, con la mano izquierda debajo de la cabe$z a$, la derecha enfrente de la cara. Sobre las piernas se halló la tibia de un bóvido; un gran vaso bicónico en la esquina inferior detrás del muerto contenía restos orgánicos indefinidos y un pequeño cuenco hemisférico. En la mandíbula se encontró un anillo de plata. El puñal y la alabarda se hallaron enfrente del cráneo, el puñal con el extremo distal apuntando hacia la cabecera, la alabarda con el extremo distal hacia arriba, en la fotografía horizontal esta última ya se observa descolocada por el desmontado de una laja lateral (Lám. I a IV).

Elementos del ajuar:

- puñal de cinco remaches (tipoAE 4); perforaciones de los cinco remaches originales rotas; probablemente como consecuencia de aquel hecho dos de las perforaciones distales fueron reemplazadas por una perforación más hacia el centro del enmangue; hoy sólo persisten restos rudimentarios de cuatro remaches; en gran parte de la zona del enmangue se conservan restos de madera con vetas ligeramente diagonal; huella de enmangue con un escote en forma de bocallave; cobre arsenicado; longitud $26.2 \mathrm{~cm}$; ancho $4.8 \mathrm{~cm}$; grosor (hoja) 0.44 $\mathrm{cm}$ (empuñadura) $0.40 \mathrm{~cm}$; peso $143 \mathrm{gr}$; grosor remaches $0.33-0.45 \mathrm{~cm}$ ( ${ }^{\circ}$ inv. 1984/157/MI/1/4) (Fig. 3a)

- alabarda (tipo AF 8); cuatro de las cinco perforaciones para remaches rotas; se conservan rudimentos de dos remaches con sección circular; huella de enmangue recta; durante la restauración se quitaron restos de madera con vetas transversal que antes existieron en la zona del enmangue y restau- rando el enmangue se taparon las perforaciones rotas; por causa de las alteraciones sufridas en la restauración, la determinación del tipo es algo problemática; en el momento del hallazgo gran parte del mango todavía se encontraba intacto, y el arma estaba parcialmente envuelta en un tejido que L. Siret interpretó como pendón; cobre arsenicado; longitud conservada $16.4 \mathrm{~cm}$; ancho $5.9 \mathrm{~cm}$; grosor (hoja) $0.56 \mathrm{~cm}$ (empuñadura) $0.27 \mathrm{~cm}$; peso $77 \mathrm{gr}$; grosor remaches $0.29-0.37 \mathrm{~cm}$ ( ${ }^{\circ}$ inv. 1984/157/ MI/1/3) (Fig. 3b)

- fragmento de otra hoja, posiblemente de una navaja de afeitar, como en uno de sus extremos aparentemente conserva el rudimento de un pedúnculo; bordes muy dañados, pero se conservan restos del biselado; roto en dos fragmentos, restaurado; retorcido en su eje longitudinal; cobre arsenicado con alto porcentaje de arsénico; longitud conservada $6.2 \mathrm{~cm}$; ancho conservado $1.8 \mathrm{~cm}$; grosor $0.86 \mathrm{~cm}$; peso $6.5 \mathrm{~cm}\left(\mathrm{n}^{\circ}\right.$ inv. 1984/157/MI/1/5) (Fig. 3d)

- arete algo irregular de plata con cuenta discoide de piedra verde; diámetro máx. $1.3 \mathrm{~cm}\left(\mathrm{n}^{\circ}\right.$ inv. 1984/157/MI/1/7) (Fig. 3c)

- gran vaso bicónico (forma 6 b); superficie bien alisada, parcialmente erosionada; de color oscilando entre marrón oscuro y negro en algunas zonas; desgrasante cuarzo de grano medio; diámetro boca $10.3 \mathrm{~cm}$; diámetro máx. $28.8 \mathrm{~cm}$; altura $23.8 \mathrm{~cm}\left(\mathrm{n}^{\circ}\right.$ inv. 1984/157/MI/1/1) (Fig. 3f)

- cuenco pequeño (forma 2 a-2); de pared fina y superficie bien alisada hasta bruñida; de color marrón oscuro hasta negro; desgrasante mica muy fina; diámetro boca $8.3 \mathrm{~cm}$; altura $4 \mathrm{~cm} \mathrm{(n \circ}$ inv. 1984/ 157/MI/1/2) (Fig. 3e)

- tibia de un bovino

Bibliografía: Siret, 1913: 455, fig. 164, lám. 13 14; Almagro Gorbea, 1976: 464; Lull, 1983: 24246; Castro Martínez et alii, 1993/94: 91-93, nota 30, tab. 1, 34, fig. 12, 14, 16; Montero Ruiz, 1994: 128, 364, n AA1149-AA1152; Torija, 1995: 8-9; Rovira Llorens et alii, 1997: 68-69, n AA1149AA1152, fig. 6, AA1152.

\section{LAS VIVIENDAS}

Si muchos aspectos del registro funerario de la Edad del Bronce en Las Herrerías siguen desconocidos, la información sobre las características del hábitat argárico aún es más incompleta. Por otra parte, como casi todos los datos sobre las vivien- 
das argáricas del yacimiento están inéditos, no se han producido confusiones ni tantos errores como en el caso de las sepulturas. Publicado de la mano de L. Siret (1907: 52) sólo existe una referencia muy breve a "unas cuantas casas que pertenecen á dicha civilisación; pero son de escasísima importancia".

También el propio Siret en sus notas presenta más organizada la descripción de los materiales del hábitat de Las Herrerías que la información sobre las tumbas. En ningún caso incluye dibujos detallados de la situación de las casas in situ, plantas o perfiles, como solía hacer con las sepulturas. Por otra parte recopiló listados numerados de las casas encontradas por concesiones mineras que ofrecen una visión sistemática, aunque no siempre completa, de los materiales recuperados, en su gran mayoría calcolíticos.

El informe que Siret nos ha dejado para la zona de la Mina Iberia no se ajuste al modelo normal de estos listados, la mayoría de los cuales fueron redactados por el arqueólogo belga aparentemente durante años posteriores. La única hoja existente no lleva fecha, pero por la mano y por la ortografía de su título "Loma de la Hiberia" se entiende que muy probablemente fuera escrita en los años ochenta o noventa del siglo XIX.Además de un croquis de la situación general (Lám. VIII), nos ofrece la descripción sumaria de tres casas encontradas en dicha loma (Expediente del MAN: Col. Siret/ caja 14/ hoja 84/ 85/ Herrerías/ 30):

"Casa $n^{\circ} 1^{\circ}$. Tiene de largura 4 metros por cuarto y $1 / 2$ hanchura y 70 centimetros hondura al sur, teniendo dos vasijas de Romanos y un alfiler y tiestos de vasijas antiguos y chapinetas agujereadas, $y$ unas perneras trabajadas.

Casa $n^{\circ} 2^{\circ}$. Se encuentra del número 1 a 21 metro[s] con 6 metros de largura y de hondura cuarenta y un centimetros, hanchura 2 metros 20 cnt. teniendo una tasa y tiestos de vasijas y una amoladera.

Casa $n^{\circ} 3^{\circ}$. Se encuentra a los 19 metros del número $1^{\circ}$ y a $111 / 2$ de $n^{\circ} 2^{\circ}$ teniendo dos metros de largura por un metro. 60 de hanchura y un departamento de 60 centimetros de largo al sur y 99 centímetros de hancho y 60 de hondura. Al norte tiene sobre el terreno virgen otro localidad con un metro ochenta de largo empezando por 40 cntrs. de hancho y rematando por 13 cntrs. de hancho al norte y 60 cntrs. de hondura encontrandose una laja con trabajo y tiestos de vasijas."

No disponemos de ninguna cronología explíci- ta para estas tres casas. Tampoco los materiales respectivos vienen dibujados, ni parece que se encuentran conservadas en la Colección Siret. No obstante, según la descripción aparentemente no se trata de plantas circulares, como cabría esperar para viviendas de época neolítica o calcolítica, y al mismo tiempo se hace referencia a útiles de piedra con inconfundible carácter prehistórico, por lo que no hay otra opción que atribuirlas a la Edad del Bronce. Probablemente son estas las "unas cuantas casas" de la Edad del Bronce a que Siret se refiere en su publicación del año 1907. Con todo, no se puede descartar por completo su adscripción al Bronce Tardío o incluso Final.

De la misma manera sólo podemos sospechar una cronología argárica para la casa mencionada por Siret en su descripción de la sepultura 1 de la Mina Alianza, suponiendo que aquí se trata de un enterramiento en cista bajo el suelo de una casa. Lamentablemente no nos ha llegado ningún listado de la mano de L. Siret que recogiera información sobre las casas de la MinaAlianza. No obstante, como en la Colección Siret se encuentran algunos vasos calcolíticos con esta procedencia, podemos dar como supuesto seguro que en este sector de Las Herrerías se localizaron más viviendas que la casa asociada a la sepultura 1 .

También las casas de los demás sectores mineros de Las Herrerías, a juzgar por los materiales descritos y dibujados en los listados respectivos, son casi exclusivamente fechables en el Calcolítico. La única excepción parece la casa 4 de la Mina Diana, explícitamente destacada por Siret entre las siete casas de esta concesión como perteneciente a la Edad del Bronce (Expediente del MAN: Col. Siret/ caja 17/3/AS.1). En este caso los materiales descritos por Siret que hoy se conservan entre los fondos del MAN permiten su indudable adscripción a la cultura de El Argar (Fig. 6). Al igual que pasa con la casa de la Mina Alianza y las distintas tumbas del sitio, es imposible localizar las casas de la Mina Diana con alguna precisión. También se desconocen las fechas de su excavación, así como cualquier detalle del hallazgo. Los mismos problemas se presentan con los escasos restos argáricos descubiertos por Siret en sus excavaciones en el vecino Villaricos, cuyo carácter y localización exacta se nos escapan (Delibes et alii, 1996: tab. 1, fig. 2). Por último hay que señalar que Siret (1907: 52), sin dar más detalles, también alude a la existencia de restos de la Edad del Bronce en las colinas al otro margen del río Almanzora, al lado de la hoya del

T. P., 57, n. ${ }^{\circ} 1,2000$ 

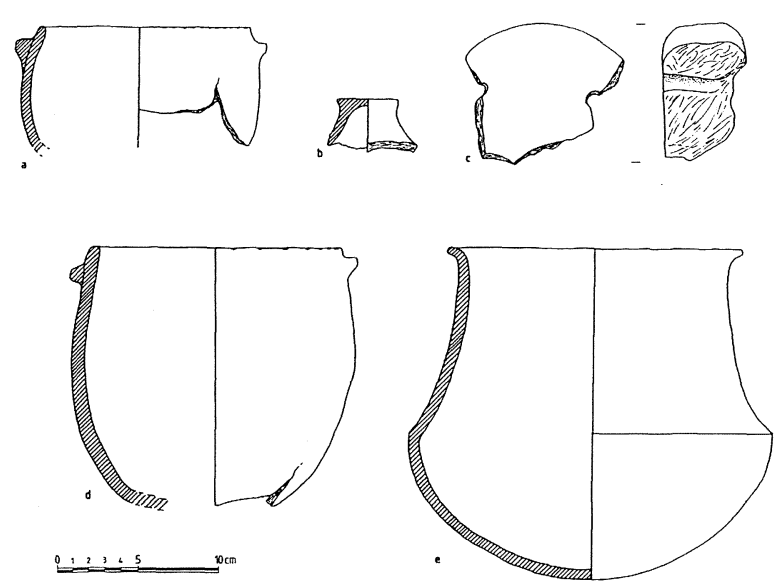

Fig. 6. Materiales cerámicos de la casa $n^{\circ} 4$ de la Mina Diana.

Algarrobo. Las prospecciones de los años ochenta lograron localizar tanto los vestigios que dejaron las actividades de Siret en este paraje, como los restos de su excavación en el vecino yacimiento argárico del Cortijo Soler, a unos $2 \mathrm{Km}$ río Almanzora arriba (Delibes et alii, 1996: tab. 1, fig. 2). No obstante, la distancia que mantienen estos últimos yacimientos en relación a los restos argáricos encontrados en los distintos sectores de Las Herrerías, nos obliga a considerarlos ya como asentamientos independientes, aunque seguramente interrelacionados.

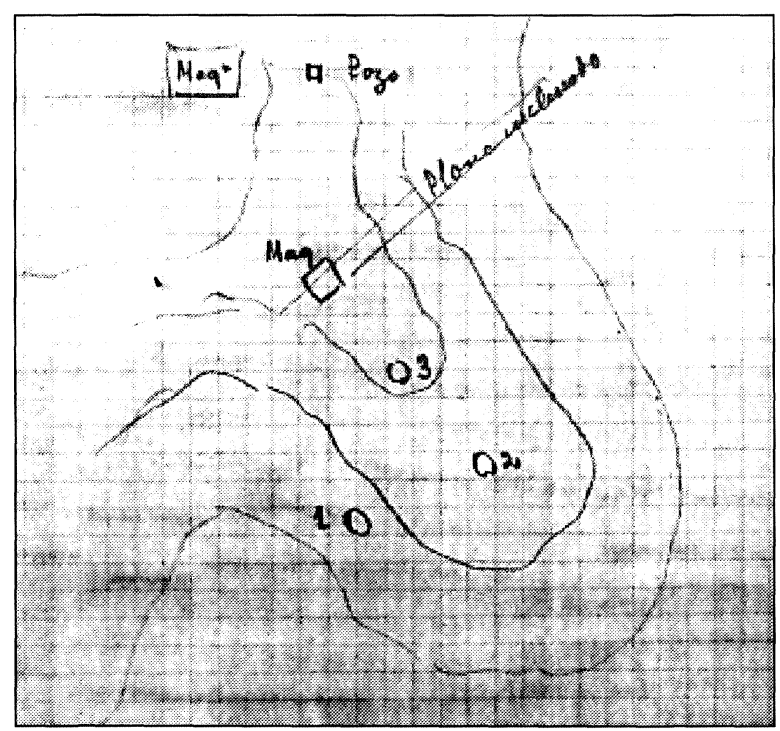

Lám. VIII. Localización de las casas argáricas en la Loma de la Mina Iberia según croquis de mano desconocido (Archivo del MAN).

\section{DESCRIPCIÓN DE LOS MATERIALES ARGÁRICOS DE LA MINA DIANA (CASA 4)}

Las piezas carecen de números individuales de inventario, por lo cual se dan como referencias los números de la caja y bolsas en que quedan almacenados en el MAN. Figuran en el listado con croquis de Siret los siguientes materiales:

- vaso carenado (forma 5b); fragmentado en varios trozos, restaurado; muy bien alisado; cocción clara-rojiza con manchas oscuras; desgrasante mica y cuarzo de grano fino hasta medio; diámetro boca $18.1 \mathrm{~cm}$; diámetro máx. $22 \mathrm{~cm}$; altura $20 \mathrm{~cm}$ (caja Mina Diana, suelta) (Fig. 6e)

- olla (forma 3b); fragmentada, sólo se conservan cinco fragmentos restaurados, falta el fondo; con dos mamelones en el borde; borde decorado con muescas; superficie poco alisada y bastante erosionada; cocción muy oscura con manchas rojizas debajo el borde; desgrasante cuarzo de grano fino y medio; diámetro boca $15.3 \mathrm{~cm}$; diámetro máx. $17.2 \mathrm{~cm}$; altura conservada $15.5 \mathrm{~cm}$ (caja 2286, suelta) (Fig. 6d)

- olla (forma 3); sólo se conservan dos fragmentos del borde; uno de los fragmentos lleva mamelón; borde decorado con muescas; superficie poco alisada; cocción oscura con manchas rojizas; desgrasante cuarzo de grano fino y medio; diámetro boca aprox. $15.3 \mathrm{~cm}$; diámetro máx. aprox.14.5 $\mathrm{cm}$; altura conservada $7.2 \mathrm{~cm}$ (caja 2286, suelta) (Fig. 6a)

- pie de una copa (forma 7); aparece como "cuello de copa" en las notas de Siret; superficie bien alisada; principal desgrasante mica; diámetro superior $3.7 \mathrm{~cm}$; diámetro inferior $4.9 \mathrm{~cm}$; altura conserv. $3.3 \mathrm{~cm}$ (caja 2286, bolsa 1) (Fig. 6b)

- fragmento de una pesa de telar; con restos de dos perforaciones; viene como "torta de barro" en las notas de Siret; desgrasante cuarzo de grano muy grueso; largo conserv. $9.3 \mathrm{~cm}$; ancho conserv. 9.9 $\mathrm{cm}$; grosor $5.7 \mathrm{~cm}$ (caja 2286, bolsa 1) (Fig. 6c)

- dos fragmentos de una o dos lajas de pizarra; identificada por Siret como "tapadera", pero en un principio quizá utilizada como piedra de frotar; largo 10.5 y $5.5 \mathrm{~cm}$; ancho 7 y $3.8 \mathrm{~cm}$; grosor 2.5 y 2 $\mathrm{cm}$ respectivamente (caja 2286, suelto y bolsa 1 respectivamente)

- "fragmentos de dos hachas empleadas como percutores" según las notas de Siret; largo 7 y 5.3 $\mathrm{cm}$; ancho 4 y $4.6 \mathrm{~cm}$; grosor 5.7 y $3.2 \mathrm{~cm}$ respectivamente (caja 2286, bolsa 1)

- 22 conchas de moluscos; figuran como "capa 
[sic.] pectunc." en los apuntes de Siret (caja 2286, bolsa 2)

- diez fragmentos de cerámica muy gruesa; de recipientes grandes, figuran como "fragmentos gruesos" en los apuntes de Siret; cocción irregular, con mucha mica y en algunos fragmentos también con cuarzo como desgrasante (caja 2286, sueltos)

Los siguientes materiales no figuran en el listado de Siret, pero hoy día se guardan en el MAN junto con las piezas allí mencionadas en la misma caja, con la misma procedencia de "Mina Diana, casa 4":

- nueve fragmentos de cerámica; aparentemente de cuencos u ollas de distintos tamaños, sin que sea posible determinar su forma exacta; de características similares a los anteriores (caja 2286, bolsa 1)

- tres fragmentos de cerámica muy gruesa; dos de las cuales con restos de asas; cocción bastante clara; desgrasante mica y cuarzo de grano medio (caja 2286, bolsa 3 )

- cinco fragmentos de cerámica; aparentemente de un cuenco; con borde decorado por muescas y dos mamelones cada uno; superficie bien alisada; cocción bastante oscura; desgrasante cuarzo muy fino (caja 2286, bolsa 4)

- un fragmento de cerámica deformado por fuerte cocción secundaria; color rojizo (caja 2286, suelto)

- alisador; largo $10.7 \mathrm{~cm}$; ancho $7.7 \mathrm{~cm}$; grosor $2.7 \mathrm{~cm}$ (caja 2286, suelto)

- mitad de un percutor; largo $5.9 \mathrm{~cm}$; ancho 6.5 $\mathrm{cm}$; grosor $2.4 \mathrm{~cm}$ (caja 2286, suelto) bolsa 2)

- costilla de un mamífero grande (caja 2286,

\section{CONCLUSIONES}

A pesar del carácter sumamente incompleto de la documentación que poseemos sobre la ocupación argárica de Las Herrerías, parece posible obtener unas conclusiones generales sobre el carácter y la cronología del yacimiento.

En cuanto a la cronología relativa, el ajuar de la cista de la Mina Iberia tanto por sus principales elementos metálicos - puñal largo del tipo AE 4 y alabarda del tipo AF 8- como por sus constituyentes cerámicos -gran vaso bicónico de la forma $6 \mathrm{~b}$ en combinación con un cuenco de la forma $2 \mathrm{a}-2-$ permite encuadrar esta tumba en la fase A 2 b del Bronce del Sudeste, establecido sobre todo en base a los datos estratigráficos de Fuente Álamo así como a una seriación de materiales de este mismo yaci- miento, de ElArgar y El Oficio (Brandherm, 1998: 171, fig. 1). La fecha carbono 14 de la cista de la Mina Iberia permite una aproximación a la cronología absoluta de este ajuar, situada en el 2125-1935 cal BC (Castro Martínez et alii, 1993/94: tab. 1,34). $\mathrm{Al}$ contrario, esta fecha no puede ser empleada para datar la alabarda de dos remaches que en general la bibliografía ha atribuido a este ajuar, pero que pertenece a la sepultura 2 de la Mina Alianza.

Dado la falta de una documentación detallada, dentro del marco de la cronología relativa sólo se puede fechar a la mencionada sepultura 2 de la Mina Alianza de forma provisional. Aunque sí es verdad que desde un punto de vista tipológico el ajuar metálico de esta tumba en comparación con las piezas de la Mina Iberia parece algo más evolucionado, la combinación de todos los elementos del conjunto tampoco permite afirmar una posición más allá de la fase A 2 b. Por la escasez de sus materialès, la sepultura 1 de la MinaAlianza también resulta difícil de fechar en términos de una cronología relativa. Una atribución a la misma fase A 2 $\mathrm{b}$ parece tan probable como su inclusión ya en la siguiente fase B 1. Lamentablemente no resulta posible atribuir directamente una fecha absoluta a uno de los ajuares de la Mina Alianza.

Por falta de elementos que permitieran una identificación cronológica más exacta, y disponiendo solamente de un vaso forma $5 \mathrm{~b}$ como indicador cronológico, también la casa 4 de la Mina Diana sólo puede ser atribuida a un amplio margen entre las fases A 2 y B 1 del Bronce del Sudeste. Según la evidencia funeraria, y siempre con esta limitación, la ocupación argárica de Las Herrerías solo queda reflejada durante lo que Lull (1983: 455) llegó a llamar la "fase del apogeo" de la cultura de El Argar. No hay pruebas de una ocupación argárica de Las Herrerías durante una fase formativa de la cultura, ni durante su última fase, atribuible ya a un Bronce Medio reciente.

Mirando ahora al carácter del yacimiento en general y a su estructura espacial en particular, quedan patentes las mismas restricciones que ya pudimos observar con relación a su definición cronológica. Con excepción de las tres casas de la Loma de Iberia desconocemos por completo la ubicación exacta de los restos argáricos documentados por $\mathrm{L}$. Siret. No obstante, las informaciones que ofrece en sus notas permiten unas afirmaciones positivas quizá no muy precisas pero sí importantes.

Por ejemplo, el número muy superior de casas calcolíticas (seis) de la Mina Diana en comparación 
con la singular vivienda argárica en este sector permite, hasta cierto punto, una contrastación de la representatividad de la muestra, al igual que los numerosos restos de época púnica, romana y medieval documentados por Siret (1907: 41-50). Con toda esta información no parece entonces admisible interpretar la casa 4 de la Mina Diana como resto único y aislado de una ocupación argárica mucho más densa y de características urbanas, víctima ya en su época de la destrucción avanzada del yacimiento por las labores de minería. Tampoco la propia situación topográfica habla en favor de una ocupación densa y concentrada como la que podemos encontrar en muchos poblados argáricos. La concesión minera de la Mina Diana se encuentra localizada al norte del Cerro Virtud, ya en pleno llano ocupado por el actual pueblo de Las Herrerías. La situación de los hallazgos de la Mina Diana corresponde más bien a la situación de asentamientos de llanura como El Rincón de Almendricos, LaAlcanara o Los Cipreses en el término de Lorca (Ayala Juan, 1977/78: 5-10; 1991: 74-131; Martínez Rodríguez et alii, 1996: 22-23). Lo mismo puede decirse de la vecina concesión de la Mina Alianza. Aquí incluso Siret al referirse en sus notas a la probable casa argárica y a la sepultura 1 de la Mina Alianza las sitúa explícitamente "en el llano de Las Herrerías" (Expediente del MAN: Col. Siret/ caja 14/ AD.1-AD.21). Lamentablemente sus apuntes en este caso no permiten ninguna contrastación con la situación durante el Calcolítico o periodos posteriores.

Tampoco en el Cerro Virtud, sitio lógico para buscar los vestigios de una posible "acrópolis" argárica, se detectó ningún indicio de un núcleo argárico con construcciones comunitarias o edificios de carácter público, como en los casos de El Oficio, Fuente Álamo y otros yacimientos principales de la cultura argárica (Brandherm, 1996: 45-46. 55). La afirmación de Siret (1907: 71) de haber encontrado abundantes restos de época neolítica en la cúspide del cerro descarta la posibilidad de especular sobre una destrucción total y completa de una hipotética "acrópolis" argárica ya en tiempos del propio Siret. Finalmente, durante las prospecciones y excavaciones recientes en el Cerro Virtud, que -eso sí- lograron documentar la casi total destrucción de los niveles arqueológicos por los trabajos de minería efectuados hasta los años cuarenta de nuestro siglo, tampoco aparecieron materiales argáricos removidos (Montero Ruiz y Ruiz Taboada, 1996: 57-58). En esta zona Siret sólo logró encontrar al- guna tumba y casas aisladas de la Edad del Bronce, dispersas en la Loma de Iberia.

En cuanto a la ocupación calcolítica de Las Herrerías no parece lícito intentar valorar los restos aparecidos en las distintas labores de minería sin tener en cuenta el núcleo de Almizaraque. Aquí tenemos que volver a insistir otra vez más que la supuesta ocupación argárica de Almizaraque, aún defendida por Lull (1983: 244-246) en su tratamiento monográfico de la cultura de El Argar, se debe a una lectura errónea del registro arqueológico en las excavaciones de los sesenta (vease Almagro Basch, 1965: 378-379). En consecuencia, durante la Edad del Bronce, ni para Almizaraque, ni para ningún otro sector de Las Herrerías contamos con una ocupación de intensidad similar a la del Calcolítico.

Todo esto no quiere decir que la ocupación argárica de Las Herrerías hubiese consistido nada más que en media docena de casas dispersas con sus respectivas sepulturas. Dado el carácter de las obras, parece bien posible y incluso probable que en los distintos sectores mineros se destruyeran algunas otras casas argáricas y sus correspondientes tumbas. Sin embargo, basandose en las informaciones proporcionados por el propio Siret, es muy improbable que fueran centenares las casas y tumbas destruidas sin su conocimiento. No estaríamos entonces ante un poblado del rango del propio ElArgar, El Oficio o de San Antón de Orihuela, donde los hermanos Siret y el Padre Furgús respectivamente documentaron varios centenares de sepulturas, sino ante un asentamiento disperso, de extensión espacial considerable y casi seguro ocupando una superficie bastante mayor que los otros asentamientos argáricos de llanura que conocemos.

Como carecemos de datos estructurales más detallados y como prácticamente no disponemos de datos económicos del asentamiento, resulta sumamente difícil juzgar el papel de este yacimiento dentro del marco del poblamiento argárico en el Bajo Almanzora. La muestra de materiales argáricos conservados no permite hablar de actividades económicas especializadas. Los percutores, el alisador y la pesa de telar de la casa 4 de la Mina Diana en este sentido no constituyen elementos suficientes. Como ya indica Lull (1983: 245), no poseemos indicios directos de la explotación de los minerales de plata, plomo y cobre del Cerro Virtud durante la Edad del Bronce. Con todo, no se puede excluir una explotación de la abundante plata nativa a partir de la época argárica, lo que, de todos modos, no hubie- 
ra dejado vestigios en el registro arqueológico y que no queda reflejado de una manera apreciable en la estructura del asentamiento.

Otro factor que hay que tener en cuenta en este contexto es la situación del yacimiento sobre la desembocadura del río Almanzora, en teoría asignando a este asentamiento una considerable importancia como "comunidad de paso" en las comunicaciones del grupo argárico del Bajo Almanzora con el Mediterráneo y permitiendo a la población argárica de Las Herrerías el control sobre el flujo de items exóticos, asociado a la noción de alto prestigio. Dado el carácter rudimentario de los restos documentados, la falta de tales items en el registro conocido no debiera ser sobrevalorado. Un problema bastante más aparente, dadas las facilidades de control teórico que el poblado argárico de Las Herrerías fue capaz de ejercer sobre distintas producciones de alto valor, como la plata y los items exóticos de la cuenca del Mediterráneo, está en el carácter abierto del asentamiento y en la aparente ausencia de toda estructura defensiva artificial, cuando tales producciones debieran haber constituido un incentivo importante para posibles agresores. Que no podemos contar con un ambiente del todo pacífico para la población argárica de Las Herrerías queda suficientemente demostrado por las armas encontradas en las sepulturas. Una posible explicación muy sencilla sería que ni la supuesta explotación de la plata, ni el supuesto papel como "comunidad de paso" correspondían a la realidad prehistórica.

En este caso, el poblado argárico de Las Herrerías se diferencia solamente por su considerable extensión y su acceso directo a recursos marinos de los asentamientos argáricos de llanura, detectados hasta ahora sobre todo en la zona de Lorca y al parecer dedicados exclusivamente a la producción primaria.

La única alternativa viable a este escenario consiste en suponer que la población argárica de Las Herrerías formaba parte de una formación social de dimensiones mayores, que por el grado de su organización estaba en condiciones de garantizar un cierto mínimo de seguridad dentro del territorio que englobaba, sin que -por falta de evidencias empíricas suficientes en el caso concreto-nos atrevamos a defender aquí la noción de un "estado argárico" en un sentido estrictamente histórico-materialista, como fue propuesto recientemente por varios autores (Risch y Ruiz Parra, 1994: 80-87; Lull y Risch, 1995: 97-109). Como los armas en las tumbas in- dican claramente, la situación seguramente habrá sido algo más compleja que la noción algo simplista de una "explotación de los críaderos de Herrerías", propuesta por Siret (1907: 53) con motivo de la plata argárica.

Son, por tanto, obvias las dificultades para situar la ocupación argárica de Las Herrerías dentro de una trayectoria diacrónica. Como ya hemos expuesto más arriba, y en contra de la opinión de Lull (1983: 245), apoyandose en el falso supuesto de una ocupación argárica de Almizaraque con fuertes tradiciones calcolíticas, no hay indicios fiables que permitan afirmar una continuidad entre la ocupación calcolítica de Las Herrerías y el asentamiento de la Edad del Bronce. Hay que tener presente, no obstante, que la gran mayoría de los restos argáricos de Las Herrerías seguramente fueron destruidos por los trabajos de minería desde el siglo pasado sin haber sido documentados. Tampoco la falta de referencias a restos del Bronce Tardío en los apuntes de L. Siret o entre los materiales de su colección debe ser sobrevalorada, dado tanto la inexistencia total de vestigios funerarios relacionados con aquella fase, como el carácter poco llamativo de sus restos materiales y, sobre todo, la falta de un concepto correspondiente antes de los años sesenta de nuestro siglo. De los inicios del Bronce Final conocemos de Las Herrerías una espada que guarda bastante afinidad con el tipo Ballintober (Siret, 1913: lám. 15), y para la época orientalizante las tumbas de la Loma de Boliche nos permiten valorar el papel importante que Herrerías tuvo que desempeñar en el entorno indígena del vecino emporion fenicio de Villaricos (Osuna Ruiz y Remesal Rodríguez, 1981:373-411). Lamentablemente, por desconocer la localización exacta y el carácter de los restos argáricos aparecidos en las excavaciones de Siret en Villaricos, hasta el momento resulta imposible avanzar conclusiones fiables acerca de su relación con el poblamiento argárico de Las Herrerías.

Considerando el grado de destrucción de este último yacimiento, tampoco futuras investigaciones en Las Herrerías tendrán mucha probabilidad de aportar nuevos datos que permitan resolver los problemas indicados. Pero en lo que se refiere a los poblados fenicios y sus contrapartidas indígenas, por lo menos el hábitat litoral como tal es conocido de una manera más o menos satisfactoria según los casos concretos. No se puede decir lo mismo del hábitat litoral en el Sudeste durante la Edad del Bronce. Aquí muchas preguntas aún quedan abiertas, ya que ha sido un aspecto en el que durante

T. P., 57, n. ${ }^{\circ} 1,2000$ 
mucho tiempo la investigación ha prestado relativamente poca atención. Dado que en las excavaciones de asentamientos fenicios -con la posible pero lamentablemente muy mal documentada excepción de Villaricos-casi nunca han aparecido restos argáricos o vestigios del Bronce Tardío, parece obvio por lo menos que la ocupación litoral siguió patrones algo distintos. Identificarlos y elaborar modelos para su entendimiento será una tarea crucial para una mejor lectura de la dinámica espacio-hábitat durante toda la prehistoria reciente en el sur de la Península Ibérica. Una atención particular en este contexto merece el papel de los núcleos argáricos de la fachada litoral granadina-malagueña en los procesos de "argarización" de las areas interiores de estas dos provincias. Hasta ahora la investigación aquí se ha fijado casi exclusivamente en las rutas terrestres, siguiendo el curso del río Almanzora o pasando por el altiplano de Chirivel.

Se plantea entonces como una de las tareas de la futura investigación establecer los parámetros y las características del hábitat litoral de la cultura de El Argar, permitiendo así valorar su papel en relación con otros yacimientos contemporáneos y dentro de una trayectoria diacrónica, contrastando la hipótesis de posibles relaciones de carácter jerárquico entre distintas clases de poblados. La urgencia de esta tarea parece aun más evidente si consideramos que el hábitat litoral tanto de la cultura argárica como de otras entidades culturales prehistóricas hoy más que nunca se ve enfrentado a una amenaza cada vez mayor, causada por la creciente explotación turística de la franja litoral del Sudeste.

\section{BIBLIOGRAFÍA}

Almagro Basch, M. (1965): "El poblado de Almizaraque de Herrerías (Almería)". Atti del VI Congresso Internazionale delle Scienze Preistoriche e Protostoriche (Roma, 1962), II: Comunicazioni Sezioni I-IV. G. C. Sansoni Editore. Firenze: 378-379.

Almagro Gorbea, M. (1976): "La espada de Entrambasaguas: Aportación a la secuencia de las espadas del bronce en el norte de la Península Ibérica". XLAniversario del Centro de Estudios Montañeses, II. Diputación Provincial. Santander: 453-477.

Arteaga, O.; Hoffmann, G.; Schubart, H. y Schulz, H.D. (1988): "Geologisch-archäologische Forschungen zum Verlauf der andalusischen Mittelmeerküste". En Forschungen zur Archäologie und Geologie im Raum von Torre del Mar 1883/84. Madrider Beiträge, 14. Philipp von Zabern. Mainz: 107-126.
Ayala Juan, M.M.(1977/78): “Un yacimiento argárico de llanura: 'La Alcanara'”. Anales de la Universidad de Murcia, Facultad de Filosofía y Letras, 36 (fasc. 1-2): 5-10.

- (1991): El poblamiento argárico en Lorca: Estado de la cuestión. Real Academia Alfonso X el Sabio. Murcia.

Baldomero Navarro, A.; Ferrer Palma, J.E. y Villaseca DíAz, F. (1985): "El Lagar de las Ánimas (Málaga)". Baetica, 8: 121-133.

Baldomero Navarro, A.; Ferrer Palma, J. E. y Marqués Merelo, L. (1988): "Excavaciones de la Universidad de Málaga, durante 1987, en yacimientos de prehistoria reciente". Baetica, 11: 153-162.

Blance, B. (1971): Die Anfänge der Metallurgie auf der Iberischen Halbinsel. Studien zu den Anfängen der Metallurgie, 4. Gebr. Mann Verlag. Berlin.

BrandHeRM, D. (1996): "Zur Nordprovinz der El ArgarKultur". Madrider Mitteilungen, 37: 37-59.

- (1998): "El Argar and Iberian Bell Beakers: Contributions towards the Relative Chronology of the Earlier Bronze Age in the Iberian Peninsula". Proceedings of the XIII Congress of the International Union of Prehistoric and Protohistoric Sciences (Forli - Italia, 8-14 September 1996), Vol. 4: Section 11: The Bronze Age in Europe and the Mediterranean, Subsection: The Early Bronze Age. A.B.A.C.O. Edizioni. Forlì: 169176.

- (e.p.): Die Dolche und Stabdolche der Steinkupfer- und der älteren Bronzezeit auf der Iberischen Halbinsel. Prähistorische Bronzefunde, VI, 12. Franz SteinerVerlag. Stuttgart.

Castro Martínez, P.V.; Chapman, R.W.; Gili Suriñach, S.; Lull, V.; Micó Pérez, R.; Rihuete Herada, C.; Risch, R. y SanAhuJA YLl, M. ${ }^{a}$ E. (1993/94): "Tiempos sociales de los contextos funerarios argáricos". Anales de Prehistoria y Arqueología, 9/10: 77-105.

Delibes, G.; Díaz-Andreu, M.; Fernández-Posse, M. ${ }^{a}$ D.; Martín, C.; Montero, I.; Muñoz, I.K. y Ruiz, A. (1996): "Poblamiento y desarrollo cultural en la cuenca de Vera durante la prehistoria reciente." En M. ${ }^{a}$ Á. Querol y T. Chapa (eds.): Homenaje al Profesor Manuel Fernández-Miranda, I. Complutum Extra, 6 (I). Servicio de Publicaciones Universidad Complutense. Madrid: $153-170$.

Guía (1954): Museo Arqueológico Nacional. Guías de los Museos de España, 1. Dirección General de Bellas Artes. Madrid.

Junghans, S.; SAngmeister, E. y Schröder, M. (1968a): Kupfer und Bronze in der frühen Metallzeit Europas: Tafeln, Tabellen, Diagramme, Karten. Studien zu den Anfängen der Metallurgie; 2,2. Gebr. Mann Verlag. Berlin.

- (1968b): Kupfer und Bronze in der frühen Metallzeit Europas: Katalog der Analysen Nr. 985-10040. Studien zu den Anfängen der Metallurgie, 2,3. Gebr. Mann Verlag. Berlin. 
- (1974): Kupfer und Bronze in der frühen Metallzeit Europas: Katalog derAnalysen Nr. 10041-22000 (mit Nachuntersuchungen derAnalysen Nr. 1-10040). Studien zu den Anfängen der Metallurgie, 2,4. Gebr. Mann Verlag. Berlin.

LuLl, V. (1983): La "cultura" de ElArgar: Un modelo para el estudio de las formaciones económico-sociales prehistóricas. Akal Editor. Madrid.

LuLL, V. y Risch, R. (1995): “El estado argárico". Verdolay, 7: 97-109.

Martínez Rodríguez, A.; Ponce García, J. y Ayala Juan, M.M. (1996): Las prácticas funerarias de la cultura argárica en Lorca - Murcia. Ayuntamiento de Lorca y Caja de Ahorros de Murcia. Lorca.

Molina Fajardo, F. (1983): "Almuñécar en el marco de la cultura argárica”. En F. Molina Fajardo (ed.): Almuñécar: Arqueología e historia, I. Caja Provincial de Ahorros de Granada. Granada: 3-20.

Montero Ruiz, I. (1994): El origen de la metalurgia en el sudeste de la Península Ibérica. Instituto de Estudios Almerienses. Almería.

Montero Ruiz, I. y Ruiz Taboada, A. (1996): "Enterramiento colectivo y metalurgia en el yacimiento neolítico de Cerro Virtud (Cuevas deAlmanzora, Almería)". Trabajos de Prehistoria, 53(2): 55-75.

Osuna Ruiz, M. y Remesal RodríGuez, J. (1981): "La necrópolis de Boliche (Villaricos-Almería)". Archivo de Prehistoria Levantina, 16: 373-416.

RISCH, R. y RuIz PARRA, M. (1994): "Distribución y control territorial en el Sudeste de la Península Ibérica durante el tercer y segundo milenios a.n.e.". Verdolay, 6: 77-87.

ROVIRA LloRENS, S.; MONTERo RuIZ, I. y CONSUEGRA RodRíGUEZ, S. (1997): Las primeras etapas metalúrgicas en la Península Ibérica, I: Análisis de materiales. Fundación Ortega y Gasset y Ministerio de Educación. Madrid.
Ruiz Morales, J.A. y Molina Poveda, C. (1996): "La espada argárica de La Herradura (Granada)". Cuadernos de Prehistoria y Arqueología Castellonenses, 17: 175181.

SChUBART, H. (1973): “Las alabardas tipo Montejícar”. En J. Maluquer de Motes (ed.): Estudios dedicados al Prof. Dr. Luis Pericot. Universidad de Barcelona. Barcelona: 247-269.

- (1975): “Cronología relativa de la cerámica sepulcral en la cultura de ElArgar”. Trabajos de Prehistoria, 32: 79 92.

Schubart, H. y ARteAGA, O. (1986): "Fundamentos arqueológicos para el estudio socio-económico y cultural del area de El Argar". En Homenaje a Luis Siret (19341984). Consejeria de Cultura de la Junta de Andalucia. Sevilla: 289-307.

Schubart, H. y UlREICH, H: (1991): Die Funde der südostspanischen Bronzezeit aus der Sammlung Siret. Madrider Beiträge, 17. Philipp von Zabern. Mainz.

SimÓN GARCÍA, J.L. (1997): "La Illeta: asentamiento litoral en el Mediterráneo occidental de la Edad del Bronce". En M. Olcina Doménech (ed.): La Illeta dels Banyets (El Campello, Alicante). Estudios de la Edad del Bronce y época ibérica. Serie Mayor, 1. Museo Arqueológico Provincial de Alicante. Alicante: 47-132.

SiRET, L. (1907): Villaricos y Herrerías. Antigüedades púnicas, romanas, visigóticas y árabes. Memorias de la Real Academia de la Historia. Madrid.

- (1913): Questions de chronologie et d'ethnographie ibériques: Tome I, de la fin du quarternaire a la fin $d u$ bronze. Paul Geuthner. Paris.

ToriJA, A. (1995): "La cista de Herrerías". En A. García Blanco y C. Padilla Montoya (coord.): Creencias y ritos funerarios. Serie Guías Didácticas del Museo Arqueológico Nacional, Temas 1. Madrid: 8-9. 